ISSN : 2087-2461

PENANGGUNG JAWAB Dekan FIKOM

Trimanah, M.Si.

Sekretaris Dekan

Dian Marhaeni K, M.Si

Ketua Penyunting Made Dwi Adnjani, M.Si

Sekretaris

Mubarok, M.Si

Bendahara

Umi Hidayah, S.H.

Dewan Penyunting

Trimanah, M.Si

Edi Ismoyo, M.Si

Suharyoso, S.Sos

Seksi Usaha

Endang Winarsih, S.Sos

Sirkulasi dan Distribusi

Novi, S.Sos

Alamat Redaksi

Fakultas Ilmu Komunikasi

Universitas Islam

Sultan Agung Semarang

Jl. Raya Kaligawe Km. 4

Po. Box 1054/SM

Semarang 50112

Telp. (024) 6583584

ext. $448 / 449$

Fax. (024) 6582455

email : jurnalfikom@yahoo.com
Inovasi Digital Public Relations Pada

Perguruan Tinggi Swasta di Kota Semarang

dalam Meningkatkan Citra

Agus Triyono

agustriyono7@gmail.com

119-126

Eksistensi Buruh Dalam Komunikasi Bipartit

(Upaya Membangun Kemitraan Antara

Buruh dan Pengusaha Secara Ideal di Kota Kretek)

Muhammad Zakki Mubarok

$127-139$

Implementasi Konsep Diri Pada Kelompok Gemes

(Gemuk Menawan Semarang)

Kajian Teoritis Psikologi Komunikasi tentang

Konsep Diri Pada Kelompok Gemes

(Gemuk Menawan Semarang)

Genta Maghvira

140-149

Representasi Perempuan dalam

Film Cinta Suci Zahrana

Urip Mulyadi

$150-158$

Kapitalisme, Budaya Dunia, Internasionalisasi Bahasa dan Nilai-Nilai Islam Pada Tayangan Periklanan Anak di Media Televisi Dalam Perspektif Bidang Kreatif Industri Periklanan

Dian Marhaeni Kurdaningsih

marhaeni@unissula.ac.id

159-172

Paparan Media Promosi Kesehatan

Dengan Pengetahuan Pencegahan Infeksi

Bagi Pengunjung Rumah Sakit

Besar Tirto Husodo

e-mail : besarundip4@gmail.com

Puspa Run Canti

173-177

Model Kampanye Pilkada Atasi Politik Uang

dan Sikap Pesimis Pemilih

(Telaah teoritis dan konsep implementasinya)

Hariyani

nhyani812@gmail.com

178-193 


\title{
PAPARAN MEDIA PROMOSI KESEHATAN DENGAN PENGETAHUAN PENCEGAHAN INFEKSI BAGI PENGUNJUNG RUMAH SAKIT
}

\author{
Besar Tirto Husodo*, Puspa Run Canti** \\ *Staf Pengajar Bagian Promosi Kesehatan dan Ilmu Perilaku FKM UNDIP Semarang \\ **Staf Rumah Sakit Tulung Agung \\ e-mail : besarundip4@gmail.com
}

\begin{abstract}
Nosocomial infections can develop when a person is in the hospital environment. Nosocomial Infection is one of the biggest causes of death when a person is in hospital. WHO in 2005 said, more than half of babies born in hospital care in hospital infections in Brazil were infected with Nosocomial Infection. The case mortality rate is 12 to 52 percent. In one hospital in Central Java found nosocomial infection rate in 2010 that is equal to $0.89 \%$. Regular hand washing is an important action for transmission of Nosocomial Infection, as it reduces the risk of transmitting skin microorganisms from one person to another. For the patient's visitors in the hospital pain media health promotion helps in obtaining information while waiting for the patient. The research was conducted to analyze the exposure of health promotion media of hospital with knowledge for hand hygiene practice on the patient's visitors at Inpatient Installation of RSUD Dr. Adhyatma Tugurejo Kota Semarang. Descriptive analytic research using cross sectional study approach. The sample of visitor research in Installation of Inpatient Class III RSUD Dr.Adhyatma Tugurejo, using cluster random sampling counted 63 people. ChiSquare test with alpha 0,05 as test equipment. The results showed the variables related to hand hygiene practice of inpatients ie age $(p=0,034)$, knowledge $(p=0,000)$, exposure media poster $(p=0,000)$ and exposure media leaflets $(p=0,004)$. Variables not related to hand hygiene practices of inpatients were gender $(p=0.837)$. Periodically RSUD Dr. Adhyatma Tugurejo needs to conduct monitoring and evaluation of health promotion media on hand hygiene. Media Promotion Healthy hand hygiene that is easy to see, has an attractive design, clear content with easy to understand language will improve the knowledge, attitude, and practice of hand hygiene of patient's visitors in the hospital.
\end{abstract}

Keywords: Hand Hygiene, Hospital Health Promotion Media, Patient Guest

\begin{abstract}
Abstrak
Infeksi Nosokomial di dapat dan berkembang saat seseorang berada dilingkungan rumah sakit. Infeksi Nosokomial salah satu penyebab kematian terbesar pada saat seseorang berada di rumah sakit. WHO tahun 2005, lebih dari separuh bayi lahir yang di rawat di bagian perawatan bayi di rumah sakit di Brasil tertular Infeksi Nosokomial. Angka kematian kasus tersebut mencapai 12 hingga 52 persen. Di salah satu rumah sakit di Jawa Tengah ditemukan angka infeksi nosokomial pada tahun 2010 yaitu sebesar $0,89 \%$. Mencuci tangan secara rutin adalah tindakan terpenting untuk mencegah penularan Infeksi Nosokomial, karena mampu mengurangi risiko penularan mikroorganisme kulit dari satu orang ke orang lain. Bagi pengunjung pasien di rumah sakit keberadaan media promosi kesehatan membantu dalam memperoleh informasi disaat menunggu pasien. Penelitian dilakukan untuk menganalisis paparan media promosi kesehatan rumah sakit dengan pengetahuan untuk praktik hand hygiene pada pengunjung pasien di Instalasi Rawat Inap RSUD Dr. Adhyatma Tugurejo Kota Semarang. Penelitian secara deskriptif analitik menggunakan pendekatan cross sectional study. Sampel penelitian pengunjung pasien di Instalasi Rawat Inap kelas III RSUD Dr.Adhyatma Tugurejo,
\end{abstract}


menggunakan cluster random sampling sebanyak 63 orang. Uji Chi-Square dengan alpha 0,05 sebagai alat uji. Hasil penelitian menunjukkan variabel yang berhubungan dengan praktik hand hygiene pengunjung pasien rawat inap yaitu usia $(\mathrm{p}=0,034)$, pengetahuan $(\mathrm{p}=0,000)$, paparan media poster $(\mathrm{p}=0,000)$ dan paparan media leaflet $(\mathrm{p}=0,004)$. Variabel yang tidak berhubungan dengan praktik hand hygiene pengunjung pasien rawat inap yaitu jenis kelamin $(p=0,837)$. Secara periodik RSUD Dr. Adhyatma Tugurejo perlu melakukan monitoring dan evaluasi media - media promosi kesehatan rumah sakit mengenai hand hygiene. Media Promosi Kesehatan hand hygiene yang mudah dilihat, memiliki desain yang menarik, isi/konten yang jelas dengan bahasa yang mudah dipahami akan meningkatkan pengetahuan, sikap, dan praktik hand hygiene pengunjung pasien di rumah sakit.

Kata kunci: Hand Hygiene, Media Promosi Kesehatan Rumah Sakit, Pengunjung Pasien

\section{PENDAHULUAN}

Infeksi Nosokomial di dapat dan berkembang saat seseorang berada dilingkungan rumah sakit. Infeksi Nosokomial salah satu penyebab kematian terbesar pada saat seseorang berada di rumah sakit. Prevalensi infeksi nosokomial pada negara berkembang bervariasi antara 5,7\% - 19,1\% dengan rata-rata lebih dari $10 \%$ angka kejadian (WHO 2010). Di Jawa Tengah, angka infeksi Nosokomial di RSUD Setjonegoro mengalami peningkatan dari tahun 2010 sd 2011 (dari $0,37 \%$ menjadi $1,48 \%$ kasus) (Nugraheni et al. 2012).

Mencuci tangan sebelum dan sesudah mengunjugi pasien merupakan salah satu cara dalam mencegah Infeksi Nosokomial, karena mampu mengurangi risiko penularan mikroorganisme kulit dari satu orang ke orang lain.

Munculnya kejadian infeksi nosokomial dapat menyebabkan turunnya kualitas mutu pelayanan medis, sehingga perlu adanya upaya pencegahan dan pengendaliannya. Cara paling ampuh untuk mencegah infeksi nosokomial adalah dengan menjalankan Standard Precaution yang salah satunya adalah dengan mencuci tangan pada setiap penanganan pasien di rumah sakit. ${ }^{(3)}$

Seorang pengunjung pasien atau pasien itu sendiri rentan terhadap masuknya mikroorganisme, jika tubuh orang tersebut terdapat pintu masuk yang dapat digunakan untuk jalan masuk mikroorganisme tersebut. Pasien, petugas kesehatan, keluarga dan pengunjung pasien merupakan kelompok yang paling berisiko terjadinya infeksi nosokomial, karena infeksi ini dapat menular dari pasien ke petugas kesehatan, dari pasien ke pengunjung atau keluarga pasien ataupun dari petugas ke pasien.

Promosi Kesehatan di RSUD Adhyatma Semarang, dalam bentuk Media Cetak Poster yang ditempatkan pada lokasi-lokasi strategis dan Media Cetak Leaflet, diharapkan dapat membantu pengunjung pasien dalam memperoleh informasi disaat menunggu pasien. Pengetahuan dari Media cetak dapat menumbuhkan kesadaran bagi Pengunjung Pasien dalam Melakukan Praktik Cuci Tangan sebelum dan sesudah mengunjungi pasien.

\section{METODE PENELITIAN}

Penelitian secara deskriptif analitik menggunakan pendekatan cross sectional study. Sampel penelitian pengunjung pasien di Instalasi Rawat Inap kelas III RSUD Dr.Adhyatma Tugurejo. Populasi pada penelitian ini adalah pengunjung pasien di Instalasi Rawat Inap RSUD Dr. Adhyatma Tugurejo Kota Semarang, sejumlah 183 orang.

Dari populasi 183 dengan Teknik pengambilan proportional random sampling. Teknik ini digunakan karena populasi terdiri dari unit yang mempunyai karakteristik yang berbeda atau heterogen dan berstrata secara proporsinal didapat jumlah responden yaitumlah 63 orang.

\section{HASIL}
A. Usia dengan Praktik Hand Hygiene Pengunjung Pasien

Tabel 1 Tabulasi Silang Usia dengan Praktik Hand Hygiene Pengunjung Pasien 
Besar Tirto Husodo, Puspa Run Canti

\begin{tabular}{|c|c|c|c|c|c|c|}
\hline \multirow{3}{*}{ Kelompok Usia } & \multicolumn{4}{|c|}{ Praktik Hand Hygiene } & \multirow{2}{*}{\multicolumn{2}{|c|}{ Jumlah }} \\
\hline & \multicolumn{2}{|c|}{$\begin{array}{l}\text { Tidak } \\
\text { Praktik }\end{array}$} & \multicolumn{2}{|c|}{ Praktik } & & \\
\hline & $f$ & $\%$ & $f$ & $\%$ & $f$ & $\%$ \\
\hline $\begin{array}{l}\text { Usia Muda } \\
\text { (18 - } 40 \text { tahun) }\end{array}$ & 4 & 13,8 & 25 & 86,2 & 29 & 100,0 \\
\hline $\begin{array}{l}\text { Usia Tua } \\
(41-60 \text { tahun })\end{array}$ & 14 & 41,2 & 20 & 58,8 & 34 & 100,0 \\
\hline$\alpha=0,05 \quad p=0,003$ & & & & & $\mathrm{Ho}=$ & $=$ ditolak \\
\hline
\end{tabular}

34 responden Usia Tua melakukan Praktek hand hygiene. Usia responden dengan praktik hand hygiene pengunjung pasien menunjukkan nilai $\mathrm{p} 0,003<0,05$ yang artinya $\mathrm{H}_{0}$ ditolak. Ada hubungan antara usia responden dengan praktik hand hygiene pengunjung pasien.

\section{B. Jenis Kelamin dengan Praktik Hand Hygiene Pengunjung Pasien}

Tabel 2. Tabulasi Silang Jenis Kelamin dengan Praktik Hand Hygiene

\begin{tabular}{|c|c|c|c|c|c|c|}
\hline \multirow{3}{*}{$\begin{array}{c}\text { Jenis } \\
\text { Kelamin }\end{array}$} & \multicolumn{4}{|c|}{ Praktik Hand Hygiene } & \multirow{2}{*}{\multicolumn{2}{|c|}{ Jumlah }} \\
\hline & \multicolumn{2}{|c|}{ Tidak Praktik } & \multicolumn{2}{|c|}{ Praktik } & & \\
\hline & $f$ & $\%$ & $f$ & $\%$ & $f$ & $\%$ \\
\hline Laki - laki & 6 & 25,0 & 18 & 75,0 & 24 & 100,0 \\
\hline Perempuan & 7 & 28,0 & 32 & 82,0 & 39 & 100,0 \\
\hline $\begin{array}{l}\alpha=0,05 \quad p \\
=0,837\end{array}$ & & & & & & \\
\hline
\end{tabular}

32 Responden perempuan yang melakukan praktik Hand Hygiene. Jenis kelamin responden dengan praktik hand hygiene pengunjung pasien menunjukkan nilai p 0,837 >0,05 yang artinya $\mathrm{H}_{0}$ diterima. Tidak ada hubungan antara jenis kelamin responden dengan praktik hand hygiene pengunjung pasien.

\section{Pengetahuan dengan Praktik Hand Hygiene Pengunjung Pasien}

Tabel 3. Pengetahuan Pengetahuan dengan Praktik Hand Hygiene Pengunjung Pasien

\begin{tabular}{|c|c|c|c|c|c|c|}
\hline \multirow{3}{*}{ Pengetahuan } & \multicolumn{4}{|c|}{ Praktik Hand Hygiene } & \multirow{2}{*}{\multicolumn{2}{|c|}{ Jumlah }} \\
\hline & \multicolumn{2}{|c|}{ Tidak Praktik } & \multicolumn{2}{|c|}{ Praktik } & & \\
\hline & $f$ & $\%$ & $f$ & $\%$ & $f$ & $\%$ \\
\hline Kurang baik & 17 & 50,0 & 17 & 50,0 & 34 & 100,0 \\
\hline Baik & 1 & 3,4 & 28 & 96,6 & 29 & 100,0 \\
\hline $\begin{array}{l}a=0,05 \\
p=0,000\end{array}$ & & & & \multicolumn{3}{|c|}{$\mathrm{Ho}=$ ditolak } \\
\hline
\end{tabular}

Paparan Media Promosi Kesehatan dengan Pengetahuan Pencegahan Infeksi Bagi Pengunjung Rumah Sakit

28 responden dengan tingkat pengetahuan baik melakukan praktik hand hygiene Tingkat pengetahuan responden dengan praktik hand hygiene pengunjung pasien menunjukkan nilai $\mathrm{p} 0,000<0,05$ yang artinya $\mathrm{H}_{0}$ ditolak. Ada hubungan antara pengetahuan dengan praktik hand hygiene pengunjung pasien.

\section{Paparan Media Poster dengan Praktik Hand Hygiene Pengunjung Pasien}

Tabel 4. Paparan Media Informasi dengan Praktik Hand Hygiene Pengunjung Pasien

\begin{tabular}{lcccccc}
\hline \multirow{2}{*}{$\begin{array}{c}\text { Paparan Media } \\
\text { Informasi }\end{array}$} & \multicolumn{3}{c}{ Praktik Hand Hygiene } & \multirow{2}{*}{ Jumlah } \\
\cline { 2 - 6 } & \multicolumn{2}{c}{ Tidak Praktik } & \multicolumn{2}{c}{ Praktik } & & \\
\cline { 2 - 6 } & $\mathrm{f}$ & $\%$ & $\mathrm{f}$ & $\%$ & $\mathrm{f}$ & $\%$ \\
\hline Kurang terpapar & 17 & 50,0 & 17 & 50,0 & 34 & 100,0 \\
Terpapar & 1 & 3,4 & 28 & 96,6 & 29 & 100,0 \\
\hline$a=0,05$ & & & & \multicolumn{3}{c}{ Ho = ditolak } \\
$p=0,000$ & & & & & \\
\hline
\end{tabular}

28 responden terpapar media poster hand hygiene melakukan praktik hand hygiene . Paparan media poster dengan praktik hand hygiene pengunjung pasien menunjukkan nilai $\mathrm{p} 0,000<0,05$ artinya $\mathrm{H}_{0}$ ditolak. Ada hubungan antara paparan media poster dengan praktik hand hygiene pengunjung pasien.

\section{E. Paparan Media Leaflet dengan Praktik Hand Hygiene Pengunjung Pasien}

Tabel 5. Paparan Media Cetak dengan Praktik Hand Hygiene Pengunjung Pasien

\begin{tabular}{|c|c|c|c|c|c|c|}
\hline \multirow{3}{*}{$\begin{array}{c}\text { Paparan Media } \\
\text { Cetak }\end{array}$} & \multicolumn{4}{|c|}{ Praktik Hand Hygiene } & \multirow{2}{*}{\multicolumn{2}{|c|}{ Jumlah }} \\
\hline & \multicolumn{2}{|c|}{ Tidak Praktik } & \multicolumn{2}{|c|}{ Praktik } & & \\
\hline & $f$ & $\%$ & $f$ & $\%$ & $f$ & $\%$ \\
\hline Kurang terpapar & 10 & 58,8 & 7 & 41,2 & 17 & 100,0 \\
\hline Terpapar & 8 & 17,2 & 38 & 82,6 & 46 & 100,0 \\
\hline $\begin{array}{l}a=0,05 \\
p=0,004\end{array}$ & & & & & \multicolumn{2}{|c|}{$\mathrm{Ho}=$ ditolak } \\
\hline
\end{tabular}

38 responden terpapar media leaflet hand hygiene di rumah sakit melakukan praktik. Praktik hand hygiene pengunjung pasien menunjukkan nilai $\mathrm{p} 0,004<0,05$ yang artinya $\mathrm{H}_{0}$ ditolak. Ada hubungan antara paparan media leaflet dengan praktik hand hygiene pengunjung pasien. 


\section{PEMBAHASAN}

Kebutuhan pengunjung pasien mengenai pesan hand hygiene sejalan dengan Uses and Gratification theory bahwa pengunjung pasien memiliki kebutuhan secara psikologis dan sosial, yang menimbulkan harapan tertentu dari media. Media poster dan leaflet hand hygiene dapat memenuhi kebutuhan ini karena sesuai dengan keinginan pengunjung pasien. Karena pengunjung pasien dilihat sebagai individu aktif dan memiliki tujuan, mereka bertanggung jawab dalam pemilihan media yang akan mereka gunakan untuk memenuhi kebutuhan mereka dan individu ini tahu kebutuhan mereka dan bagaimana memenuhinya. Media dianggap hanya menjadi salah satu cara pemenuhan kebutuhan dan individu bisa jadi menggunakan media untuk memenuhi kebutuhan mereka, atau tidak menggunakan media dan memilih cara lain.

Sejalan dengan pendapat Notoatmodjo (2012), bahwa suatu praktik mempunyai beberapa tingkatan, yaitu:

\section{Respons terpimpin (guided response)}

Dapat melakukan sesuatu sesuai dengan urutan yang benar dan sesuai dengan contoh merupakan indikator praktik tingkat pertama. Dalam media cetak hand hygiene tercantum secara runut langkaha-langkah cuci tangan pakai sabun. Pemakaian Gambar memudahkan pembaca dalam memahami pesan yang di sampaikan.

\section{Mekanisne (mecanism)}

Apabila seseorang telah dapat melakukan sesuatu dengan benar secara otomatis, atau sesuai itu sudah merupakan kebiasaan, maka ia sudah mencapai praktik tingkat kedua. Salah satu media cetak yang digunakan ada pemakaian gambar atau foto mengenai kebiasaan hand hygiene dapat di mulai dengan langkah sederhana di mana sehari2 sudah sering di lakukan.

\section{Adopsi (adoption)}

Adopsi adalah suatu tindakan atau praktik yang sudah berkembang dengan baik. Artinya, tindakan itu sudah dimodifikasi tanpa mengurangi kebenaran tindakan tersebut. Media cetak memberikan gambaran yang utuh bahwa hand hygiene dapat memakai sabun apa saja apabila sabun ati septik tidak tersedia.

\section{SIMPULAN}

1. Kemudahan informasi dalam media poster dan media leaflet dari segi desain, bahasa, isi dan kemasan secara keseluruhan memudahkan pengunjung pasien dalam mendapatkan informasi mengenai hand hygiene.

2. Media leaflet hand hygiene dikemas menarik, mudah di simpan dan suatu saat bila memerlukan informasi lagi dapat di baca ulang.

\section{Rekomendasi}

1. Memperjelas isi pesan hand hygiene pada media cetak dengan variasi kemasan pesan dengan menambahkan informasi bagianbagian tangan yang harus dibersihkan saat hand hygiene.

2. Meningkatkan strategi promosi media poster MMT dam leaflet hand hygiene berupa peningkatan kualitas (design, susunankata/kalimat, ukuran), peningkatan jumlah, dan lokasi penempatan yang mudah dilihat pengunjung pasien.

\section{DAFTAR PUSTAKA}

Darmadi. Infeksi Nosokomial [Internet]. Problematika dan Pengendalian. Jakarta: Salemba Medika; 2013.

Saragih R., Rumapea N. Hubungan Karakteristik Perawat Dengan Tingkat Kepatuhan Perawat Melakukan Cuci Tangan di Rumah Sakit Columbia Asia Medan [Internet]. E-Journal Universitas Darma Agung Medan. 2010. Available from: http://uda.ac.id/ jurnal/files/7.pdf

James, J., Baker, HS. Prinsip-prinsip Sains untuk Keperawatan. Jakarta: Erlangga; 2002.

Azwar, A. Menjaga Mutu Pelayanan Kesehatan : Aplikasi Prinsip Lingkaran Pemecahan Masalah. Jakarta: Sinar Harapan; 1996. 
Gerna, H. Buku Ajar Infeksi dan Pediatri Tropis. 2nd ed. Jakarta: IDAI; 2008. 338-345 p.

Saifuddin, AB. Panduan Pencegahan Infeksi untuk Fasilitas Pelayanan Kesehatan dengan Sumber Daya Terbatas. Jakarta: Yayasan Bina Pustaka Sarwono Prawirohardjo; 2004. 20-1-21-10 p.

Kasmad., Sujianto, U., Hidayati, W. Hubungan Antara Kualitas Perawatan Kateter Dengan Kejadian Infeksi Nosokomial Saluran Kemih. Hub Kualitas Perawatan Kateter. 2007;1(1).

PDPERSI. 1,4 juta Kematian Akibat Infeksi di RS [Internet]. 2013 [cited 2016 Mar 20]. Available from: http://www. pdpersi.co.id/

Depkes RI. Pedoman Manajerial Pencegahan Dan Pengendalian Infeksi Di Rumah Sakit Dan Fasilitas Pelayanan Kesehatan Lainnya. Journal of Chemical Information and Modeling. Jakarta: Depkes RI; 2013. p. 1689-99.

Depkes RI. P. Pedoman Pencegahan dan Pengendalian Infeksi di Rumah Sakit dan Fasilitas Pelayanan Kesehatan Lainnya: Kesiapan Menghadapi Emerging Infectious Disease. 2nd ed. Jakarta: Depkes RI; 2008. 